\title{
The new boss in town
}

\section{Barack Obama's transition team is hitting the ground running, and its speed and openness are winning praise, as David Goldston reports.}

\section{T} he weekend after the US presidential election, I was in Chicago for a conference. At about 4 p.m. on Saturday afternoon, I stopped at a crowded coffee shop on one of the city's busiest streets and ran into two of president-elect Barack Obama's foreign-policy aides, who were working unobtrusively on their laptops at one of the small tables. "What are you doing here?" I asked, thinking that the first Saturday after a two-year campaign might be a day off. But they didn't comment about being at work. They said that the campaign office had now shut down and the transition office wasn't ready yet - so they had to work somewhere.

The story is emblematic of the Obama transition, which seems to have impressed just about everyone in Washington DC with its speed, diligence, expertise and openness. Although there have been reports of tensions at some agencies, particularly NASA, one usually partisan White House official told me that the Obama team gave him "this squishy goodgovernment feeling I don't get very often". And someone who worked on the Clinton transition noted that in 1992 "we didn't even meet" until several weeks after election day.

Although some top Obama aides remain in Chicago, the bulk of the transition operation is housed in a nondescript government building in Washington. The setting is appropriate: although the level of excitement is high and the pace frenetic, the actual work is the day-to-day stuff of government - lots of meetings, writing papers, sending ideas up the chain of command with uncertain results, and racing to meet deadlines. "It seems like there's a deadline every day," one of the transition staff lamented to me. "They obviously can't all be meaningful."

There are two types of transition team: policy teams that are organized by topic and designed to look at big-picture issues, and review teams for each federal agency. The names of all the teams and their members are available on the transition website (www.change.gov). In an unprecedented move, the site also posts all the written proposals that interest groups have submitted. The transparency is refreshing and has been lauded by public-interest groups, although it could limit the kinds of ideas the transition teams hear. Some groups may be reluctant to 'think out loud' or to offer ideas that diverge from their party line because everything

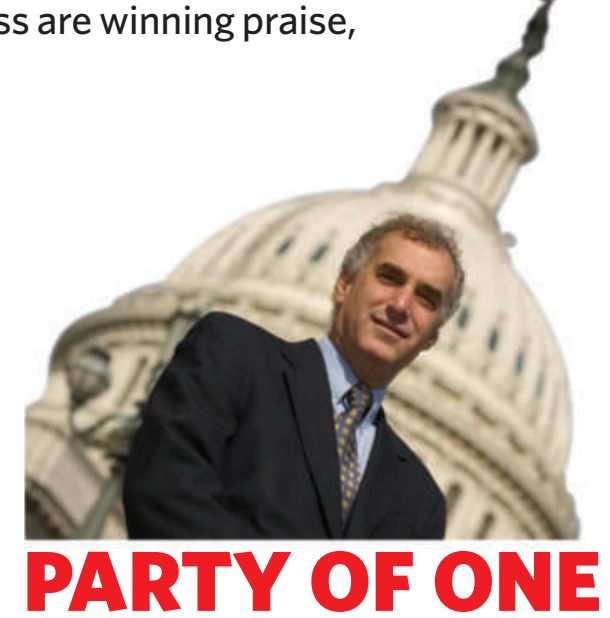

will become public. But no one seems to be complaining. "We may take an extra day before sending something in" to make sure it's fully vetted, but the content is basically the same, said Tobin Smith of the Association of American Universities. Unsurprisingly, transparency does not extend to internal recommendations to Obama. The transition team has not been making its own papers public, and its members have been told not to speak to the media.

Although the transition team has been soliciting ideas on every imaginable issue, in early December, as economic news became ever more grim, the stimulus package that Obama hopes to see enacted in January began to dominate. Putting together multibillion-dollar proposals at high-speed is a little "disconcerting", one of the transition staff told me, noting that most of the team members are more used to worrying about budget constraints. Smith said Tom Kalil, a top transition official on science and innovation, called him on Monday 8 December and said he needed any ideas for a stimulus bill by that Thursday.

As the economy worsened, the criteria for what might be included in a bill apparently broadened. Smith said that earlier on, the teams seemed to be looking only for stimulus projects that could spend all their money in a year; by December that had stretched to three-year projects. "They realized that it can take projects a while to ramp up," said Smith, although they still want ideas that are "shovel-ready".

The transition team has been running its proposals past the career staff at the Office of Management and Budget (OMB), an OMB staffer told me. He said that the OMB has been asked to review technical matters such as whether the numbers look realistic and how quickly the money could be spent. In policy areas in which the OMB and transition staff have a good and open relationship, discussions of the proposals can be extensive. The transition teams have eliminated or altered spending ideas because of OMB guidance, he said.

Before the stimulus temporarily shunted everything else aside, the transition teams had been meeting with just about every group under the sun on a wide range of policies. Francesca Grifo, who heads the Union of Concerned Scientists' work on scientific integrity, said she has participated in about five meetings with teams covering relevant agencies. "In some cases, we reached out to them," she said, "in others, they asked to meet with us." The Environmental Protection Agency transition team asked the group to set up a meeting of scientific and public-interest groups that had worked on scientific-integrity issues. Transition sources indicate that Obama is likely to issue an executive order on scientific integrity shortly after taking office. At all the meetings, Grifo said, the transition teams asked many questions, but were careful not to give away anything about their own thinking.

Smith noted that science groups are playing a much more active role in this transition than in past ones, partly because Obama's team has been open and partly because of concerns that have accumulated during the Bush administration. "We started being active during the campaigns," he said. "And for the first time, we recommended names" of people for science and education posts.

The teams have also been meeting with each federal agency. The transition team for the Office of Science and Technology Policy (OSTP) has met with all the political and career staff at the OSTP at least once, a White House official told me. The meetings have been candid and friendly, and have focused on decisions that will need to be made in the first 100 days, such as questions on the switch from analogue to digital television, the shutdown of the space-shuttle programme, and the Intergovernmental Panel on Climate Change. Classified matters have had to wait because the OSTP transition team does not yet have the necessary clearances.

The official said it was very helpful that some of the OSTP transition team had served in the Clinton administration and understood the White House operation. But still, he said, at a human level, the process left him with a "funny feeling. You see the transition team walking around with their badges in a building you think of as your place, and you realize it's not your place any more."

David Goldston is a project director at the Bipartisan Policy Center in Washington DC. Reach him at partyofonecolumn@gmail.com. 